\title{
Is Lifelong Knee Joint Force from Work, Home, and Sport Related to Knee Osteoarthritis?
}

\author{
Charles R. Ratzlaff, ${ }^{1}$ Mieke Koehoorn, ${ }^{2}$ Jolanda Cibere, ${ }^{3,4}$ and Jacek A. Kopec ${ }^{2,3}$ \\ ${ }^{1}$ Division of Rheumatology, Immunology, and Allergy, Brigham and Women's Hospital, 75 Francis Street PBB3, Boston, \\ MA 02115, USA \\ ${ }^{2}$ School of Population and Public Health, University of British Columbia, 5804 Fairview Avenue, Mather Building, \\ Vancouver, BC, Canada V6T $1 Z 3$ \\ ${ }^{3}$ Arthritis Research Centre of Canada, 895 West 10th Avenue, Vancouver, BC, Canada V5Z 1L7 \\ ${ }^{4}$ Division of Rheumatology, University of British Columbia and Gordon \& Leslie Diamond Health Centre, 10th Floor, \\ 2775 Laurel Street, Vancouver, BC, Canada V5Z 1 M9
}

Correspondence should be addressed to Charles R. Ratzlaff, cratzlaff@partners.org

Received 14 January 2012; Revised 14 May 2012; Accepted 14 May 2012

Academic Editor: Fahad Hanna

Copyright ( $) 2012$ Charles R. Ratzlaff et al. This is an open access article distributed under the Creative Commons Attribution License, which permits unrestricted use, distribution, and reproduction in any medium, provided the original work is properly cited.

\begin{abstract}
Purpose. To investigate the association of cumulative lifetime knee joint force on the risk of self-reported medically-diagnosed knee osteoarthritis (OA). Methods. Exposure data on lifetime physical activity type (occupational, household, sport/recreation) and dose (frequency, intensity, duration) were collected from 4,269 Canadian men and women as part of the Physical Activity and Joint Heath cohort study. Subjects were ranked in terms of the "cumulative peak force index", a measure of lifetime mechanical knee force. Multivariable logistic regression was conducted to obtain adjusted effects for mean lifetime knee force on the risk of knee OA. Results. High levels of total lifetime, occupational and household-related force were associated with an increased in risk of OA, with odds ratio's ranging from approximately 1.3 to 2. Joint injury, high BMI and older age were related to risk of knee OA, consistent with previous studies. Conclusions. A newly developed measure of lifetime mechanical knee force from physical activity was employed to estimate the risk of self-reported, medically-diagnosed knee OA. While there are limitations, this paper suggests that high levels of total lifetime force (all domains combined), and occupational force in men and household force in women were risk factors for knee OA.
\end{abstract}

\section{Introduction}

The promotion of physical activity (PA) is a major public health initiative in many countries due to its protective effect on numerous major health problems [1], including Canada and the US where public health bodies recommend 30 to 60 minutes of moderate-to-vigorous activities per day. However, there has long been a concern that such promotion could lead to a rise in hip and knee OA, the major public health problem in musculoskeletal medicine and a leading cause of chronic disability [2]. While there is a broad agreement that PA is an important determinant of joint health, it is unclear what amount and type of PA are beneficial or pose a risk. In short, despite numerous studies, the association between PA and joint health is complex and poorly understood.
While different study designs, case definitions, sampling frames, and size play a role, the wide variation in how PA is defined is the most probable reason for the uncertainty. There is a lack of valid, reliable, and standardized instruments across studies, substantial measurement error, variation in the period and nature of PA measured, and failure to measure the most relevant aspect of PA-joint load [3]. Where accurate and precise measures are available, they are impractical for use in population-based research. The goals of this study were to address these gaps by (1) measuring historic PA, a key variable given the long latency and asymptomatic induction period of OA that, while potentially imprecise, is likely more important than accurate measure of an irrelevant variable such as current activity, (2) examining loads applied to the joint using quantitative joint loading 
units that allowed for assessment of cumulative force from $\mathrm{PA}$, including dose response, and (3) including household activity (in addition to occupation and sport/recreation) to capture all three primary domains of activity.

The purpose of this study was to evaluate the association between levels of lifetime knee joint force and knee OA in a large Canadian sample of community dwelling adults.

\section{Methods}

Data Source and Study Population. The source population was community-dwelling members of the Canadian Association of Retired Persons, Canada's largest 50-plus advocacy group with 350,000 members. Data collection methods have been previously described $[4,5]$. Briefly, recruitment was via direct email to 28,000 members and to 100,000 additional members via an advertisement in an online newsletter, appearing in two consecutive newsletters. All e-mails and newsletters contained hyperlinks or banner advertisements directing subjects to the study website. Through these methods, subjects across Canada were recruited over the Internet. Incentives included $\$ 1,500$ in lottery prizes. After completing an electronic consent form, subjects were given password access to the questionnaire. All data collection was web-based and used skip logic technology that allowed subjects to follow individualized paths through the survey, moving forward based on responses to previous questions. Extensive pre- and pilot-testing was carried out to ascertain best recruitment methods [6], survey duration, navigation, and to ensure that respondents could understand items, retrieve information, and make appropriate estimations. A secure website for the study allowed subjects to save responses and return later. The baseline questionnaire, carried out from June to September 2005, took 60 to 90 minutes to be completed.

Response rates have been previously described [4] and are presented in Figure 1. Individuals who completed the baseline survey were contacted by email and letter for followup surveys at approximately one (May 2006) and two years (June 2007). Follow-up surveys inquired about knee joint health using the same questions as the baseline survey.

2.1. Design. A period prevalence study using a cross-sectional design was utilized, as there were an insufficient number of incident knee OA cases to power the study to meet the objectives. To compile the dataset, subjects reporting OA at any of the three time points (Figure 1) were identified as cases. Baseline exposure data was used. While the inclusion of prevalent cases could potentially limit the ability to delineate cause and effect, the approach was justified on several grounds, and steps were taken to guard against reverse causality. First, increasing the number of cases by combining prevalent and incident cases allowed for greater study power to assess gender-specific relationships between $\mathrm{PA}$ and $\mathrm{OA}$ while including a number of covariates, and assessing dose-response relationship of PA with OA. Second, a new measure of exposure-quantitative lifelong joint force from work, sport, and household activity measured in joint loading units-was investigated for the first time. Third, the relationship between the historic PA measured in this study (up to age 50, as discussed in Methods) and the time of diagnosis for the vast majority of cases is separated in time, providing some protection against reverse causality. In addition, the highest levels of lifetime PA for most people occur prior to the age of 50 [5]. Lastly, since OA is not a curable condition, prevalence is a relatively stable reflection of disease frequency.

2.2. Physical Activity Measurement. Lifetime physical activity was assessed using the Lifetime Physical Activity Questionnaire (L-PAQ), whose development and validation has been described previously [7]. In summary, the L-PAQ is a selfadministered, web-based questionnaire that was based on existing instruments [8-10], developed using the principles of construct validation, adapted for self-administration over the Internet, incorporated skip logic technology, and expanded to capture more detailed information including bodily movements involving the knee. Using a subsample of the current study, intraclass coefficients for reliability ranged from 0.65 to 0.89 ; convergent validity testing against two validated lifetime questionnaires resulted in Spearman correlation coefficients ranged from 0.41 to 0.71 [7].

The LPAQ measures lifetime PA across three domains: sport/recreation, occupation, and household and had been described previously $[4,5]$. Sample questions in each domain are shown in Appendix A. Briefly, in the sports/recreational section, respondents were provided with a list of 64 possible sports and were permitted to add other sports. Data collected included the duration, frequency, and average length of time per occasion, and time spent per hour (none, 1-5, 5-15, $15-30,30-45$, and 45-60 minutes per hour) in eight bodily positions or movements. The occupational section used an open format in which respondents, for each occupation ever held, provided details on job title or type, duration, average hours per week, and whether the job was full time, part time, or seasonal and time spent per eight-hour segment in nine bodily positions or movements. Household activity covered four areas: (1) caring for children; (2) caring for elderly or disabled individuals; (3) gardening; (4) housework. For each household area of activity, participants were prompted to provide detailed information on duration and average number of hours per week of participation and were required to report time spent in an 8-hour period for each of the bodily movements as per the occupational section (Appendix B-list of activities and assigned joint force).

\subsection{Cumulative Peak Force Index (Bodyweight-Hours). To} obtain a measure of cumulative joint force at the knee, a cumulative peak force index (CPFI) score was estimated at the knee and has been described previously [5] as the product of time spent in a specific activity (total lifetime hours), bodyweight (BW), and typical peak joint force for that activity (\%BW), (i.e., CPFI score (bodyweight-hours) = total lifetime hours $*$ bodyweight $*$ typical peak joint force, per each activity).

As previously described $[4,5]$, the CPFI is a newly proposed measure, and steps were taken to validate and/or 
2005 invitees-Canadian Association of Retired Persons

Two methods

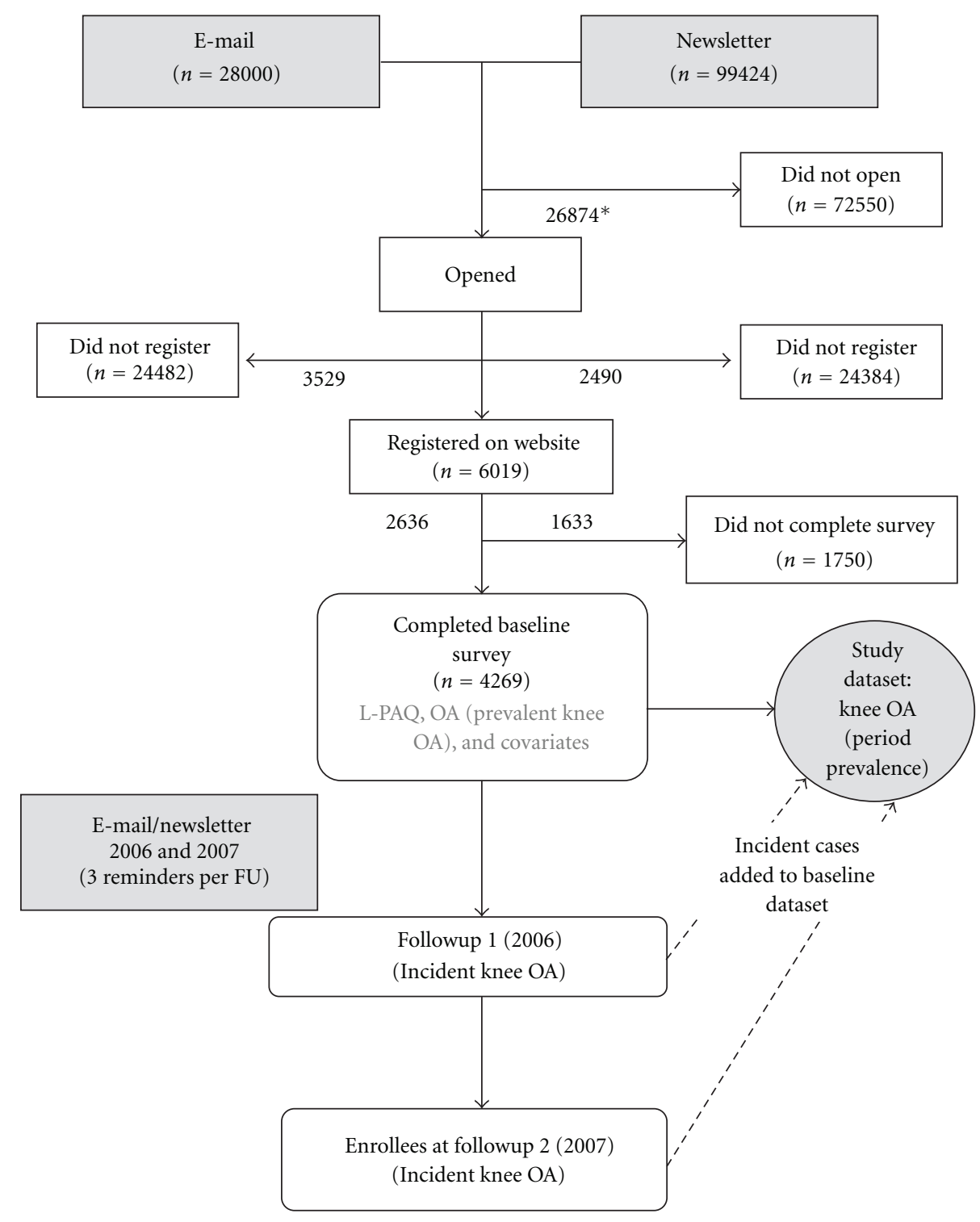

*Values in flow chart are number of subjects at each stage of recruitment/enrolment

FIgure 1: Lifetime Physical Activity and Joint Health Study: recruitment and enrolment.

ensure the greatest precision in the components that comprise it. In addition to validation of the L-PAQ [7], selfreported bodyweight and height were utilized, measures with established validity properties [11] used in numerous epidemiologic studies. We improved on a single self-report of bodyweight by asking about it at three time points (baseline survey, age 20, maximum lifetime), and deriving a lifetime bodyweight trajectory, interpolated using a Lowess (nonparametric smooth) curve. The third component of the measure was the typical peak joint force assigned to each activity (Appendix B). These values were determined after an extensive literature [12-40] (full bibliography available on request) that prioritized in vivo studies and incorporated judgments about data quality and study rigor. Data were synthesized and a consensus achieved by a panel of experts from biomechanical engineering, rheumatology, physiotherapy, and musculoskeletal epidemiology.

The force exposure variable was operationalized as exposure prior to the age of 50. The main reason for this was to capture the primary PA exposure prior to the diagnosis of OA (and first symptoms) for the vast majority of cases, and to minimize the effects of subclinical, undiagnosed, or 
early OA on PA patterns. Support for this approach was also drawn from the previous study on lifetime trajectories [5] that revealed that peak exposure window for PA is prior to 50 , being at its highest lifetime levels from ages 30-45.

2.4. Case Ascertainment. An algorithm was used to ascertain knee OA cases, requiring that subjects report both "health-

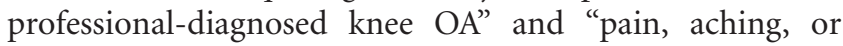
stiffness on most days" at any of the 3 time points (baseline, 1 st and 2 nd followups). The questionnaire item on healthprofessional-diagnosed OA informed subjects that OA was distinct from other MSK diseases (e.g., rheumatoid arthritis and osteoporosis), and a response confirmation to this question was required in a follow-up item.

The reliability and validity of self-reported knee OA was carried out in a substudy and has been previously published [41]. Briefly, using the American College of Rheumatology (ACR) clinical classification criteria for knee OA [42] as a diagnostic referent, sensitivity was 0.76 , specificity 0.98 , positive predictive value 0.87 , and negative predictive value 0.95. Kappa value was 0.76 indicating substantial agreement beyond chance [43]. Our findings are consistent with other studies comparing self-report medically diagnosed OA and clinical OA [44-46].

2.5. Covariates. The baseline questionnaire measured known knee health risk factors and included gender, age, body mass index (BMI), ethnicity (Asian, Black, Caucasian, First Nations, Hispanic, and others), and education (elementary, high school, postsecondary, and trade/technical).

2.6. Injury. The following question from the baseline questionnaire was used to determine the presence of significant knee injury: "Have you ever had a knee injury that required you to use a walking aid (e.g., cane or crutch) for at least one week?" Follow-up questions included the age at injury (if more than one injury, the time of first injury was requested). Only injuries that occurred before the diagnosis of OA were included in analysis.

2.7. Statistical Methods. The prevalence of knee OA and covariates for the study sample were calculated. CPFI values for each activity were summed for sport, occupation, and household domains for each 5-year period of a person's lifetime to factor in changes in bodyweight over time, and these domain values were then summed to give a total CPFI value [5]. For the total force (CPFI) variable, subjects were categorized into quintiles of exposure for the overall distribution, prior to stratification by gender. For the domain specific analysis, the quintiles were based on the relative distribution within each domain (occupation, household, and sport), again prior to stratification by gender (e.g., quintile 5 for occupation was at the same joint loading level for both sexes). Crude odds ratios were calculated for the relationships between knee $\mathrm{OA}$ and joint force variables and other study covariates. Potential collinearity and interaction between covariates was examined on a bivariate basis.
Covariates were selected based on scientific knowledge and the conceptual framework of causal pathways to knee OA. Factors associated with an increased risk of knee OA, which also could be confounders, such as age, previous injury, and BMI were adjusted for in all the analyses. The potential effect of one domain on another (e.g., occupational activity when assessing the sport-OA relationship) was also potentially confounding and included. Men and women were examined separately because of known gender differences in disease prevalence, physical activity profiles, injury rates, and BMI. Reference categories were the lowest CPFI, youngest age tertile $(<58)$, normal BMI (20.0-24.9), and no previous injury. Test for trends was obtained by treating the categories (quintiles) of the CPFI variable as continuous and testing the slope for significance; the models contained all relevant adjustment covariates.

Multiple logistic regression was used to examine if levels of total knee CPFI were associated with a risk of knee OA, controlling for age, previous injury, and BMI. An additional adjusted analysis was carried out investigating the separate effect of occupational, sport, and household CPFI (adjusted for the other domains). Analyses were performed using SPSS version 18 (Chicago, IL, USA).

\section{Results}

Subject characteristics for the sample are presented in Table 1. Frequencies of outcome, exposure, and covariates for this study are provided in Tables 2 and 3. The prevalence of knee OA was $22.4 \%$ for the sample overall- $17.8 \%$ for men and $25.1 \%$ for women (Table 2 ). Twenty-six percent of the sample were of normal BMI, with approximately $72 \%$ being either overweight $(39.9 \%)$ or obese $(31.5 \%)$. More men than women ( 47.7 to $36.1 \%$ ) were overweight, and more women than men were obese (33.4 to $29.5 \%$ ). Twenty percent had a history of previous knee joint injury (24\% in men and $18 \%$ in women).

The prevalence of subjects in occupational and household quintiles varied substantially by gender (Table 3 ). For example, in the male household strata, the largest prevalence $(36.3 \%)$ was in the lowest (referent) quintile of exposure, while the smallest prevalence $(6.2 \%)$ was in the highest quintile of exposure. For women, the largest prevalence $(27.5 \%)$ was in the highest quintile of exposure and the smallest prevalence in the referent quintile (11.1\%). For occupational force, these relative proportions were reversed by gender, though the percentages were slightly different (Table 3).

Crude ORs provided evidence that older age, previous knee injury, obesity in men, and overweight and obesity in women were associated with knee OA (Table 2). Compared with the lowest category of total lifetime knee force the highest category (5th quintile), in men and $3 \mathrm{rd}, 4 \mathrm{th}$, and 5 th quintiles in women were crudely related to knee OA (Table 2). For domain-specific lifetime force, the 5th quintile of occupational force in men and both occupational and household activity in and women were crudely related to OA (Table 3). 
TABLE 1: Subject characteristics $(n=4269)^{*}$.

\begin{tabular}{lccc}
\hline & Overall & Males & Females \\
\hline$N$ & 4269 & $1575(37 \%)$ & $2694(63 \%)$ \\
Mean age & $61.5(7.6)$ & $63.0(7.8)$ & $60.6(7.3)$ \\
Mean current weight (lb) & $175(41)$ & $193(41)$ & $165(38)$ \\
Mean current BMI & $27.3(5.9)$ & $27.0(5.3)$ & $27.5(6.3)$ \\
Married (\%) & 65.9 & 79.2 & 58.1 \\
Some postsecondary education (\%) & 66 & 68.8 & 64.8 \\
\hline
\end{tabular}

*Values are the mean and SD unless otherwise indicated.

TABLE 2: Crude and adjusted ${ }^{\dagger}$ odds ratios for knee $\mathrm{OA}^{*}$, by sex.

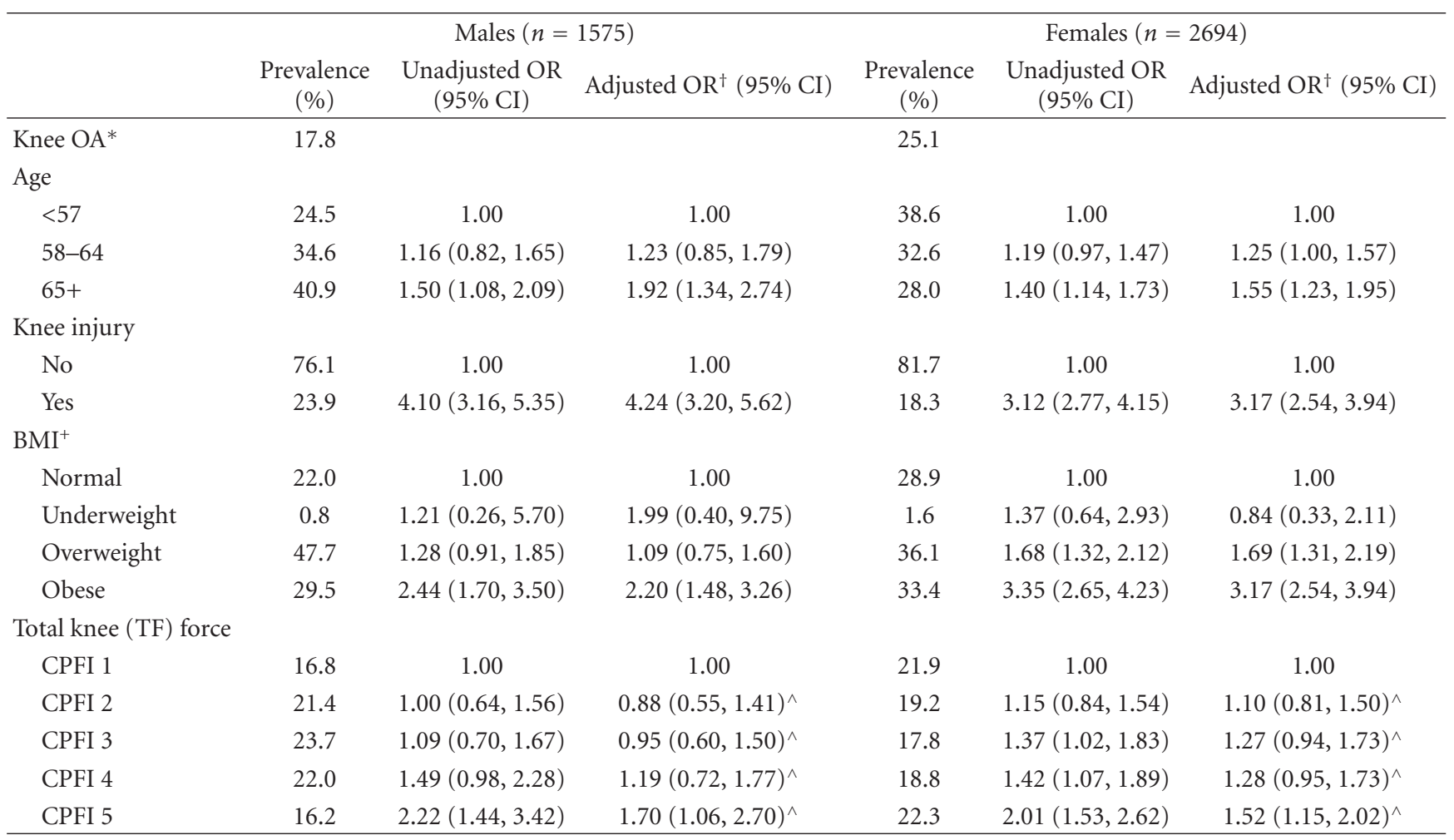

* Self-reported medical diagnosis of knee OA, plus pain, aching, or stiffness most days.

${ }^{\dagger}$ Adjusted for all other covariates in table.

+ BMI categories: normal (20-24.9), underweight (<20), overweight (25-29.9), and obese (>30.0).

${ }^{\wedge}$ Test for trend: $P<0.001$.

Adjusted ORs for risk factors on knee OA obtained from multiple logistic regression are presented in Tables 2 and 3. The strength of association for knee OA and total lifetime force remained significant for the highest force quintile in both men $(1.70 ; 95 \% \mathrm{CI}-1.06,2.70)$ and women $(1.52 ; 95 \%$ CI-1.15, 2.02). In domain-adjusted models, occupational force in men and household force in women were related to knee OA and tests for trend in these domains, as well as in total lifetime force (both men and women), were significant $(P<0.001)$.

Sport/recreational force was not related to knee OA. After adjustment, older age, injury, and high BMI remained significantly related to knee OA. Being overweight (BMI 2529.9) increased the risk of knee OA for women (OR 1.69; $95 \% \mathrm{CI}-1.31,2.19)$ but was not related to knee OA in men.
Obesity (BMI > 30) was a greater than two-fold risk for men and three-fold risk for women.

\section{Discussion}

This prevalence study on a large sample of Canadian adults presents a newly proposed measure of lifetime mechanical knee joint force based on hours in PA, bodyweight, and typical knee joint force for specific activities and relates it to self-reported knee OA. We provide evidence that while lifelong PA may generally be safe for the knee joint, that very high force from lifelong total force, and from high levels of total occupational force (men and women) and household activity (women), is a potential risk for knee OA. The results held after adjustment for known risk factors. These novel 
TABLE 3: Crude and adjusted ${ }^{\dagger}$ odds ratios for knee $\mathrm{OA}^{*}$ by activity domain and dose.

\begin{tabular}{|c|c|c|c|c|c|c|}
\hline & \multicolumn{3}{|c|}{ Males $(n=1575)$} & \multicolumn{3}{|c|}{ Females $(n=2694)$} \\
\hline & $\begin{array}{c}\text { Prevalence } \\
(\%)\end{array}$ & $\begin{array}{c}\text { Unadjusted OR } \\
(95 \% \mathrm{CI})\end{array}$ & Adjusted $\mathrm{OR}^{\dagger}(95 \% \mathrm{CI})$ & $\begin{array}{l}\text { Prevalence } \\
\quad(\%)\end{array}$ & $\begin{array}{c}\text { Unadjusted OR } \\
(95 \% \mathrm{CI})\end{array}$ & Adjusted $\mathrm{OR}^{\dagger}(95 \% \mathrm{CI})$ \\
\hline Knee OA* & 17.8 & & & 25.1 & & \\
\hline \multicolumn{7}{|c|}{ Sport Knee (TF) force } \\
\hline CPFI.1 & 12.3 & 1.00 & 1.00 & 25.1 & 1.00 & 1.00 \\
\hline CPFI.2 & 14.7 & $0.84(0.49,1.43)$ & $0.76(0.40,1.43)$ & 23.5 & $0.86(0.65,1.13)$ & $0.83(0.61,1.14)$ \\
\hline CPFI.3 & 16.3 & $0.74(0.43,1.27)$ & $0.74(0.39,1.39)$ & 22.5 & $0.80(0.60,1.06)$ & $0.72(0.52,0.99)$ \\
\hline CPFI.4 & 23.0 & $1.13(0.71,1.82)$ & $1.06(0.61,1.86)$ & 18.0 & $0.81(0.60,1.09)$ & $0.77(0.55,1.08)$ \\
\hline CPFI.5 & 33.6 & $1.24(0.79,1.93)$ & $1.13(0.66,1.93)$ & 11.0 & $0.78(0.55,1.11)$ & $0.70(0.46,1.05)$ \\
\hline \multicolumn{7}{|c|}{ Occ knee (TF) force } \\
\hline CPFI.1 & 7.5 & 1.00 & 1.00 & 27.6 & 1.00 & 1.00 \\
\hline CPFI.2 & 18.4 & $1.30(0.68,2.49)$ & $1.34(0.57,2.61)^{\wedge}$ & 21.0 & $1.17(0.89,1.53)$ & $1.03(0.73,1.43)$ \\
\hline CPFI.3 & 17.3 & $1.60(0.84,3.05)$ & $1.41(0.56,2.60)^{\wedge}$ & 21.7 & $1.25(0.96,1.63)$ & $1.16(0.84,1.60)$ \\
\hline CPFI.4 & 24.2 & $1.81(0.97,3.35)$ & $1.62(0.79,3.33)^{\wedge}$ & 17.5 & $1.26(0.95,1.66)$ & $1.05(0.74,1.49)$ \\
\hline CPFI.5 & 32.7 & $2.10(1.15,3.82)$ & $1.93(0.95,3.90)^{\wedge}$ & 12.4 & $1.81(1.34,2.44)$ & $1.37(0.95,1.98)$ \\
\hline \multicolumn{7}{|c|}{ House knee (TF) force } \\
\hline CPFI.1 & 36.3 & 1.00 & 1.00 & 11.1 & 1.00 & 1.00 \\
\hline CPFI.2 & 29.9 & $1.01(0.72,1.41)$ & $1.00(0.68,1.48)$ & 14.6 & $0.94(0.64,1.38)$ & $1.07(0.66,1.75)^{\wedge}$ \\
\hline CPFI.3 & 17.8 & $1.06(0.71,1.56)$ & $0.94(0.60,1.47)$ & 21.2 & $1.07(0.75,1.52)$ & $1.56(0.98,2.43)^{\wedge}$ \\
\hline CPFI.4 & 9.8 & $0.84(0.50,1.40)$ & $0.70(0.39,1.25)$ & 25.6 & $1.24(0.88,1.75)$ & $1.49(0.97,2.30)^{\wedge}$ \\
\hline CPFI.5 & 6.2 & $1.61(0.94,2.76)$ & $1.17(0.61,2.24)$ & 27.5 & $1.67(1.20,2.33)$ & $2.02(1.32,3.01)^{\wedge}$ \\
\hline
\end{tabular}

${ }^{*}$ Self-reported medical diagnosis plus pain, aching, or stiffness most days.

${ }^{\dagger}$ ORs adjusted for age, knee injury, BMI, and other activity domains.

${ }^{\wedge}$ Test for trend: $P<0.001$.

findings require confirmation in other populations and in longitudinal studies. Our results are consistent with previous studies that show overweight/obesity, age, female sex, and previous injury are significant risk factors for knee OA [4755].

The results of this study must be compared cautiously with previous studies due to its cross-sectional design, how subjects were assembled, and how exposures and outcomes were measured. For example, no other studies evaluating $\mathrm{PA}$ and knee OA have used the Internet for data collection or have completely classified PA in terms of a joint loading variable over the long term, perhaps partly explaining inconsistent results from these past studies [44, 56-61]. Of note, the cross-sectional design may have resulted in reverse causality potentially attenuating risk estimates. Conversely, subjects with OA may have overreported prior PA exposure because they perceive that PA caused their OA (recall bias), potentially increasing the risk estimates [56]. Since this type of bias threatens most prevalence studies, emphasis should be placed on recent high-quality cohort studies evaluating the association between PA and OA.

A recent prospective cohort study with a 22-year-followup using physician-diagnosed OA, reported an adjusted OR for the heaviest category of physical demands at work compared with the lightest category of 18.3 for knee OA [62]. Verweij et al. [63], during 12 years of followup, recently reported that 463 of 1678 respondents (28\%) developed clinical knee OA, and that a high mechanical strain score was associated with an increased risk of knee OA (HR 1.43 , 95\% CI 1.15-1.77) after adjustment for a number of covariates. Wang et al. [64], in a prospective cohort study of approximately 40,000 Australians with an average 5 years of followup, reported a composite sport and occupational exposure (past 6 months, measured at baseline) and found a risk for total knee joint arthroplasty for the vigorous level of activity (HR 1.42, 95\% CI 1.08-1.86). Several studies from the Framingham cohort suggest that job activities may cause as much as $15 \%$ to $30 \%$ of knee OA in men $[65,66]$. Felson et al. [65] reported that elderly persons (average age 70) in the highest quartile of PA at a baseline examination had over three times the risk of developing radiographic knee OA nine years later, when compared with those in the lowest quartile. McAlindon et al. [67] using longitudinal Framingham data reported that the number of hours per day of heavy physical activity was associated with the risk of incident radiographic knee $\mathrm{OA}$ ( $\mathrm{OR}=7.0$ for $4+$ hours heavy physical activity/day). No effects were observed from moderate and light PA. In contrast, a study by Hannan et al. [68] in the same cohort found no increase in the risk of knee OA with increasing physical activity. In the highest quartile of PA compared to the least active, the OR was 1.3 for men and 1.1 for women (both nonsignificant). Hart et al.[69], using data from the Chingford study, followed 715 women (mean age: 54 years) for 4 years with no radiographic knee $\mathrm{OA}$ at baseline and included the PA categories of walking, occupation, and sport/recreation. They found no relationship between 
incident knee $\mathrm{OA}$ and $\mathrm{PA}$, while walking protected against joint space narrowing $(\mathrm{OR}=0.4,95 \% \mathrm{CI} 0.2-0.9)$.

It is evident from these often-cited reports that, despite the longitudinal cohort designs, large samples and lengthy followups, and estimates for the risk of PA on knee OA vary extensively. While differences in eligibility criteria, covariates included in multivariable models and small samples may account for some of the disparity, the most likely reason is the wide variation in PA exposure measurement. Of note, most studies have not measured the joint-force aspects of PA nor attempted to completely classify PA (including historic PA) from all three major activity domains. Apart from the Verweij et al's study [63], none of the above studies considered PA from all three major activity domains or attempted to estimate the effect of activities in terms of joint force. The main finding of Verweij et al. was an OR of 1.43 (95\% CI 1.15-1.77) for a high knee mechanical strain score, close to our reported OR's from the highest quintiles of total knee force, occupational force, and household force in women. Results are not directly comparable since apart from differences in design, the mechanical strain score was a ranking (1 to 4 ) of certain physical activities over the past 2 weeks (taken at baseline) and did not look at sexspecific differences in occupational and household activity. Consistent with the recent longitudinal cohort study of Toivanen et al. [62] and a number of longitudinal and case control studies [55-57, 68-75], we did not find a relationship between sport/recreational activity and knee OA. Studies that have shown a relationship between sport and knee OA have generally been in populations of athletes in specific sports with high knee forces [54, 76-81] and not from populationbased studies, or the association has been explained by joint injury [76]. In population-based studies of lifetime activity, the highest sport/recreation rates typically occurs at a relatively young age, as it did in the current cohort, prior to the age of 25 [5]. Thus, high forces from sport later in life, when the joint may be more vulnerable, were not wellrepresented in this sample and may contribute to the lack of association here.

The prevalence of knee OA in our study was $22.4 \%$, $17.8 \%$ in men and $25.1 \%$ in women. These gender differences in prevalence are consistent with previous large populationbased North American studies for this age group [82-84]. Even though there is probably some misclassification, our definition, which required a medical diagnosis and the presence of pain on most days, is important since pain is usually the most important aspect of disease to patients and may precede X-ray change, potentially capturing earlier disease. We report the results of a validity study in a subsample of the current study comparing self-reported OA to clinical OA [41].

It was important to measure and simultaneously adjust for PA-related force from all three major activity domains. Most previous PA-OA studies have investigated one or two domains (usually sport and/or occupation). Given the high levels of household and occupational PA reported in our previous paper [5], omitting one or both of these domains leaves these studies vulnerable to confounding from the unmeasured domain(s).
In studying all three domains separately by sex, we also observed relationships of PA with very high occupational force in men and household force in women. Questionnaires used in many previous studies did not assess the frequency, duration, and intensity of PA actually performed by women [85]. The majority of women's exposure to PA, particularly in older cohorts such as the current one, is due to accumulation of regular household activities [85-88]. While household activity may generally not be considered vigorous from an energy expenditure perspective and is often ignored in epidemiologic study of OA, there are many repetitive motions (e.g., stair climbing, squatting, and kneeling) and activities (e.g., gardening, lifting, and carrying) that are associated with high knee joint forces $[20,21,28,36]$ but have low energy expenditure.

This is only the second study to measure lifelong household load at the knee joint and relate it to knee OA, and the first to quantify household knee joint force from historic activity for the assessment of dose response. In the previous study by Sandmark et al. [89], exposure to physically demanding tasks at home was significantly associated with knee OA among women (but not men) and was the strongest risk factor for women among the physical load variables that were investigated in that study. Given that women have been shown to have higher PA than men when including household together with occupational and sporting activities [5], and that reasons for the higher prevalence of knee OA in women are not clearly elucidated [51], our findings provide preliminary evidence that the role of historic household PA requires further investigation. The role of occupational activity has received much more study, and is better understood in men than in women, in part because previous studies were based historically on male-dominated workforce cohorts [51]. Even though women often spend forty or more hours a week at a fulltime job and from twenty to forty-five hours per week working in the home, questionnaires used in many previous studies do not assess the frequency, duration, and intensity of PA actually performed by women [85]. It has been shown that, when the definition of regular physical activity measured in surveys is expanded to include household activity, PA levels rise and associations with health outcomes are more evident-including protective relationships with cardiovascular disease and myocardial infarction [90], cancer [91], and an inverse relationship with all-cause mortality $[85,90]$. Our finding of an increased risk of knee OA for the top quintile of occupational joint force is generally consistent with previous studies $[62,64]$ and several systematic reviews [92-94].

The CPFI, a quantitative joint force measure, together with a large sample allowed for evaluation of a dose-response relationship between lifelong force and knee OA. In the models where a significant relationship with knee OA was found (total force, occupation, and household), there was an increasing, significant trend in the ORs from lower to higher levels of CPFI, though only the ORs for the highest (5th) quintile reached statistical significance. While this requires confirmation and further delineation in future studies, the 
presence of dose response strengthens evidence for a causal relationship [95].

This study had several strengths, including a large sample drawn from the population and a sufficient number of cases to adjust for a number of covariates, the separate analyses of men and women (equivalent to including interactions with gender for all variables), and assessment of dose-response. Another strength was the use of detailed information on the duration, frequency, and joint loading aspects of historic activities, from all three main physical activity domains, allowing for relatively complete classification of the total volume of PA. Historic PA is a potentially important exposure in OA etiology given the lengthy induction and asymptotic latency period. Measuring current or recent levels of PA does not capture long-term joint forces, may miss etiologically important periods of exposure and is a poor proxy for cumulative lifetime exposure [96]. Lastly, many studies have used advanced disease markers, such as total joint arthroplasty or moderate-to-marked radiographic change as the outcome in assessing the role of PA. It is not clear whether the relationship with PA for early, symptomatic cases is the same as that observed for advanced or radiographically defined OA. Our cases definition allowed us to capture information on earlier stages of disease. This may be important in understanding modifiable risk factors that could play a role in a prevention strategy for $\mathrm{OA}$, something not currently available.

There are a number of limitations that are important in interpreting the results of this study. Self-report of knee OA may lead to misclassification. In our examination of the measurement properties of our case definition [41], we noted that specificity was very high. This is critical for studies of risk factors, since low specificity (inclusion of many false positives among cases) causes a greater attenuation of effect than low sensitivity. PPV was also high, another important measure indicating that the vast majority of the cases identified in the survey were true cases. Nevertheless, we did not use radiography as part of the classification criteria for knee $\mathrm{OA}$. Radiographic OA in the presence of symptoms is thought to represent the best definition of OA. However, Xray change is associated largely with moderate-to-advanced disease [97], and there is only moderate agreement between pain and symptoms and X-ray changes [98]. Wu et al., in a study using a validated outcome instrument for knee OA based on arthroscopic visualization, suggest that the ACR clinical classification criteria can be used to identify patients with early articular cartilage loss, before any radiographic changes are evident [97]. However, it is probable that the false positives include not only subjects with early OA not captured by the ACR criteria [97], but also other causes of knee symptoms.

The results from this study may not be broadly generalizable. The subjects were fairly well-educated, predominantly Caucasian Canadians with access to public health care and Internet users. This method of data collection may not be as effective in low-income populations, and those with decreased access to medical care-important since we asked about medically-diagnosed osteoarthritis as part of the case definition. Further, since recruitment and enrolment of subjects was via the Internet, subjects were largely selfselected. Self-selection implies that the nature of the bias cannot be known with certainty [99]. Studies of subjects who participate in online research reveal that they are more likely to be older, females and have higher socioeconomic status [100]. Also, response rates for online recruitment and enrolment vary from traditional rates. Many more individuals potentially view invitations to participate in research, with most declining to participate, making validity of results more challenging to interpret. In online surveys, there is no single response rate-multiple metrics for calculating a response rate have been defined such as the participation rate and completion rate [101]. However, the goal of this study was not to describe characteristics of the population at large, but to assemble subjects to test hypotheses about PA-related knee joint force and knee OA in a large sample of individuals who met criteria for a disease and those who did not, sampled in the same way (internal validity).

The limitations of our measure of self-report of PA measures and construction of the CPFI variable have been discussed elsewhere $[4,5]$. In short, self-reported PA measures require cautious interpretation because of large withinperson variability and problems with recall [102-104], that may lead to nondifferential misclassification and attenuation of the effect size in analytic studies using the exposure. In particular, this attenuation may have contributed to a lack of a significant finding from the sport domain, since the highest sport levels occurred in the distant past (prior to age 25) for most subjects, are not part of the generic memory pattern (shown to have better recall) [105] and thus may been imprecisely recalled. Despite these limitations, it has been repeatedly shown that PA questionnaires are both practical and valid when used appropriately for large-scale epidemiologic studies [86, 104, 106, 107].

The CPFI, a time-force-bodyweight product, was a stronger predictor of knee OA than any of its component parts alone and is a new measure of PA-related force measured in joint loading units. However, the CPFI does not separately and specifically capture elements of activityrelated force that may be most injurious such as shear, rapid deceleration, or high-impulse loads. Activities where those elements of force occur (e.g., cutting and pivoting sports, jumping sports, and carrying heavy loads) were captured, indirectly measuring these harmful types of load, but the strength of a potential signal from these forces may have been blunted. Another potential limitation related to recall is the possibility of recall bias, where the ability to recall past exposure is dependent on outcome status. Of note, subjects with $\mathrm{OA}$ at baseline may have overreported prior PA exposure, attributing their OA to their past activity. This could lead to increased risk estimates, and while justified for the reasons outlined previously, the results remain vulnerable to this type of bias. However, risk estimates for sport and occupational exposure as well as other covariates were generally in the expected direction and consistent with the literature including prospective data [47-55], lending validity to the findings. Regardless, the possibility of this bias must be acknowledged, and study results interpreted in light of this. 
TABLE 4: Sample questions from three domains of physical activity (survey was online using skip logic technology).

Purpose of questions
Sports/recreation (u
$\begin{aligned} & \text { Questions on duration of participation in } \\ & \text { each sport activity }\end{aligned}$

Questions on frequency of participation in each sports activity

Questions on length of time of participation in one occasion of sports activity

Questions on hip joint movements (e.g., time spent in a given activity-e.g., walk, stand, run/jog, squat, lift, and jump)
Specific questions

Units

the first item in the L-PAQ sports domain, "aerobics," as an example)

Q1: At what age did you start participating in aerobics?

Q2: At what age did you stop participating in Aerobics? If you are still participating in Aerobics, please fill in your current age

Q3: How many months per year did you participate in Aerobics?

Q4: How often did you participate (per week, per month, or per year)?

Q5: On average, how long did you participate on each occasion (minutes or hours)?

Q6: When participating in Aerobics, how much time did you spend doing the following activities, on average?
YOP: years of participation

WPY: months per year converted to weeks per year

OPW: occasions per week (all units converted)

HPO: hours per occasion (all units converted)

(ordinal radio button responses in $\mathrm{min} / \mathrm{hr}$-none, $1-5 \mathrm{~min},<15$, $15-30, \ldots, 45-60)$

Occupation (using
Identify occupation
Questions on duration of participation in
each occupation
each occupation

Questions on frequency of participation in each occupation

Questions on length of time of participation in one occasion of occupation

Questions on hip joint movements (e.g., time spent in given activity-e.g., walk, stand, lift, carry, use heavy tools, squat, and lift)
Q1: Please list job number 1

Q2: At what age did you start participating in job number 1 ?

Q3: At what age did you stop participating in job number 1 ? If you are still in job number 1 , fill in your current age

Q4: What type of employment was job number 1 (full time, part time, or seasonal)?

Q5: How long was a season on average?

Q6: How many hours per week did you work on average?

Q7: When performing job number 1 how much time did you spend doing the following activities, on average?
YOP: years of participation

WPY: weeks per year (all units converted)

\section{HPW: hours per week}

(ordinal radio button responses in $\mathrm{min} / \mathrm{hr}$-none, $1-5 \mathrm{~min},<15$, $15-30, \ldots, 45-60)$

\begin{tabular}{|c|c|c|}
\hline \multicolumn{3}{|c|}{ Household (using "caring for children" from L-PAQ household domain, as an example) } \\
\hline & Q1: At what age did you begin caring for children? & \\
\hline $\begin{array}{l}\text { Questions on duration of participation of } \\
\text { domestic activity }\end{array}$ & $\begin{array}{l}\text { Q2: At what age did you stop caring for children? If } \\
\text { you are still caring for children, fill in your current } \\
\text { age }\end{array}$ & YOP: years of participation \\
\hline $\begin{array}{l}\text { Questions on frequency of participation of } \\
\text { domestic activity }\end{array}$ & *Assumed at 52 weeks per year & \\
\hline $\begin{array}{l}\text { Questions on length of time performing } \\
\text { domestic activity }\end{array}$ & $\begin{array}{l}\text { Q3: How many hours per week did you care for } \\
\text { children on average? }\end{array}$ & HPW: hours per week \\
\hline $\begin{array}{l}\text { Questions on hip joint movements (e.g., time } \\
\text { spent in given activity-e.g., walk, stand, } \\
\text { lift, carry, and squat) }\end{array}$ & $\begin{array}{l}\text { Q4: When caring for children, how much time did } \\
\text { you spend doing the following activities, on average? }\end{array}$ & $\begin{array}{l}\text { (ordinal radio button responses } \\
\text { in } \mathrm{min} / \mathrm{hr} \text {-none, } 1-5 \mathrm{~min},<15 \text {, } \\
15-30, \ldots, 45-60 \text { ) }\end{array}$ \\
\hline
\end{tabular}

Although this study provides evidence of an association between high levels of lifelong joint force, overweight/obesity, previous injury, BMI, and knee OA, the cross-sectional design makes the determination of a cause and effect more challenging. However, the time window used for the main PA exposure (prior to age 50) captures the ages [30-45] with the highest level of lifetime force and is separated in time from knee OA diagnosis for the vast majority of cases. Supporting this, most of the risk estimates for covariates reported in this study were in the expected direction and effect sizes consistent with the literature [4755], and the period prevalence design included incident cases. Lastly as this study is the first attempt to examine the effect of a new exposure measure (quantitative lifelong joint load from all three primary activity domains) on knee OA, a cross-sectional approach is reasonable. 
TABLE 5: Force value assigned to each activity in the CPFI formula. Average knee (tibiofemoral) force $(\times$ bodyweight $(\mathrm{BW}))$.

\begin{tabular}{lc}
\hline Activity & Knee force (BW) \\
\hline Stand & 1 \\
Walk & 3 \\
Run & 6 \\
Stand and hold object $>23 \mathrm{~kg}$ & $1+23 \mathrm{~kg}$ \\
Walk and carry object $>23 \mathrm{~kg}$ & $3+23 \mathrm{~kg}$ \\
Push & 3 \\
Heavy tool & 1 \\
Kneel & 0 \\
Squat & 5 \\
\hline
\end{tabular}

The finding that most PA-related force is not related to knee OA, but that the highest levels of joint force are, is biologically plausible and fits within the conceptual framework of causation. Under normal physiological conditions, the transmission and distribution of joint loads can occur for decades with little or no wear [108]. However, when normal joint physiologic mechanisms are overwhelmed via excessive local mechanical force, biologic events are triggered which destabilize the normal coupling of degradation and synthesis of articular cartilage and subchondral bone [109]. Animal studies clearly illustrate that high joint force from PA affects cartilage metabolism and plays a role in the development of OA [110-112].

In summary, a newly proposed measure of lifetime mechanical knee force was used to estimate the risk of selfreported knee OA. While it must be interpreted cautiously because of the cross-sectional design and the possibility of recall bias, this study suggests that lifelong physical activity is generally safe. High levels of lifetime knee force from occupational activity in men and women, and household activity in women were associated with knee OA. Obesity and previous injury were also a significant risk, consistent with previous studies. Prevention efforts may best be directed at occupations requiring high physical demands, at weightcontrol programs and injury prevention. Future research should further investigate the potential role of household activity, improve the estimation and validity of knee force measurement in new populations, and apply these measures in longitudinal studies.

\section{Appendices}

\section{A.}

See Table 4.

B.

See Table 5 .

\section{References}

[1] D. M. Urquhart, J. F. L. Tobing, F. S. Hanna et al., "What is the effect of physical activity on the knee joint?A systematic review," Medicine and Science in Sports and Exercise, vol. 43, no. 3, pp. 432-442, 2011.

[2] A. A. Guccione, D. T. Felson, J. J. Anderson et al., "The effects of specific medical conditions on the functional limitations of elders in the Framingham study," American Journal of Public Health, vol. 84, no. 3, pp. 351-358, 1994.

[3] C. J. Caspersen, "Physical activity epidemiology: concepts, methods, and applications to exercise science," Exercise and Sport Sciences Reviews, vol. 17, pp. 423-473, 1989.

[4] C. R. Ratzlaff, G. Steininger, P. Doerfling et al., "Influence of lifetime hip joint force on the risk of self-reported hip osteoarthritis: a community-based cohort study," Osteoarthritis and Cartilage, vol. 19, no. 4, pp. 389-398, 2011.

[5] C. R. Ratzlaff, P. Doerfling, G. Steininger et al., "Lifetime trajectory of physical activity according to energy expenditure and joint force," Arthritis Care and Research, vol. 62, no. 10, pp. 1452-1459, 2010.

[6] P. Doerfling, J. A. Kopec, M. H. Liang, and J. M. Esdaile, “The effect of cash lottery on response rates to an online health survey among members of the canadian association of retired persons: a randomized experiment," Canadian Journal of Public Health, vol. 101, no. 3, pp. 251-254, 2010.

[7] M. A. De Vera, C. Ratzlaff, P. Doerfling, and J. Kopec, "Reliability and validity of an internet-based questionnaire measuring lifetime physical activity," American Journal of Epidemiology, vol. 172, no. 10, pp. 1190-1198, 2010.

[8] C. M. Friedenreich, K. S. Courneya, and H. E. Bryant, “The lifetime total physical activity questionnaire: development and reliability," Medicine and Science in Sports and Exercise, vol. 30, no. 2, pp. 266-274, 1998.

[9] C. M. Friedenreich, K. S. Courneya, H. K. Neilson et al., "Reliability and validity of the past year total physical activity questionnaire," American Journal of Epidemiology, vol. 163, no. 10, pp. 959-970, 2006.

[10] A. Vuillemin, F. Guillemin, G. Denis, J. Huot, and C. Jeandel, "A computer-assisted assessment of lifetime physical activity: reliability and validity of the QUANTAP software," Revue d'Epidemiologie et de Sante Publique, vol. 48, no. 2, pp. 157167, 2000.

[11] R. M. Merrill and J. S. Richardson, "Validity of self-reported height, weight, and body mass index: findings from the National Health and Nutrition Examination Survey, 20012006," Preventing Chronic Disease, vol. 6, no. 4, article A121, 2009.

[12] D. D. Anderson, B. M. Hillberry, D. Teegarden, W. R. Proulx, C. M. Weaver, and T. Yoshikawa, "Biomechanical analysis of an exercise program for forces and stresses in the hip joint and femoral neck," Journal of Applied Biomechanics, vol. 12, no. 3, pp. 292-312, 1996.

[13] G. M. Kotzar, D. T. Davy, V. M. Goldberg et al., “Telemeterized in vivo hip joint force data: a report on two patients after total hip surgery," Journal of Orthopaedic Research, vol. 9, no. 5, pp. 621-633, 1991.

[14] G. M. Kotzar, D. T. Davy, J. Berilla, and V. M. Goldberg, "Torsional loads in the early postoperative period following total hip replacement," Journal of Orthopaedic Research, vol. 13, no. 6, pp. 945-955, 1995.

[15] S. Park, D. E. Krebs, and R. W. Mann, "Hip muscle cocontraction: evidence from concurrent in vivo pressure 
measurement and force estimation," Gait and Posture, vol. 10, no. 3, pp. 211-222, 1999.

[16] W. A. Hodge, R. S. Fijan, and K. L. Carlson, "Contact pressures in the human hip joint measured in vivo," Proceedings of the National Academy of Sciences of the United States of America, vol. 83, no. 9, pp. 2879-2883, 1986.

[17] D. T. Davy, G. M. Kotzar, R. H. Brown et al., "Telemetric force measurements across the hip after total arthroplasty," Journal of Bone and Joint Surgery A, vol. 70, no. 1, pp. 45-50, 1988.

[18] R. A. Brand, D. R. Pedersen, D. T. Davy, G. M. Kotzar, K. G. Heiple, and V. M. Goldberg, "Comparison of hip force calculations and measurements in the same patient," Journal of Arthroplasty, vol. 9, no. 1, pp. 45-51, 1994.

[19] B. W. Stansfield, A. C. Nicol, J. P. Paul, I. G. Kelly, F. Graichen, and G. Bergmann, "Direct comparison of calculated hip joint contact forces with those measured using instrumented implants. An evaluation of a three-dimensional mathematical model of the lower limb," Journal of Biomechanics, vol. 36, no. 7, pp. 929-936, 2003.

[20] W. R. Taylor, M. O. Heller, G. Bergmann, and G. N. Duda, "Tibio-femoral loading during human gait and stair climbing," Journal of Orthopaedic Research, vol. 22, no. 3, pp. 625632, 2004.

[21] G. Bergmann, G. Deuretzbacher, M. Heller et al., "Hip contact forces and gait patterns from routine activities," Journal of Biomechanics, vol. 34, no. 7, pp. 859-871, 2001.

[22] G. Bergmann, F. Graichen, and A. Rohlmann, "Hip joint loading during walking and running, measured in two patients," Journal of Biomechanics, vol. 26, no. 8, pp. 969-990, 1993.

[23] E. B. Simonsen, P. Dyhre-Poulsen, M. Voigt, P. Aagaard, G. Sjogaard, and F. Bojsen-Moller, "Bone-on-bone forces during loaded and unloaded walking," Acta Anatomica, vol. 152, no. 2, pp. 133-142, 1995.

[24] A. J. van den Bogert, L. Read, and B. M. Nigg, "An analysis of hip joint loading during walking, running, and skiing," Medicine and Science in Sports and Exercise, vol. 31, no. 1, pp. 131-142, 1999.

[25] G. Nemeth, J. Ekholm, and U. P. Arborelius, "Hip joint load and muscular activation during rising exercises," Scandinavian Journal of Rehabilitation Medicine, vol. 16, no. 3, pp. 93$102,1984$.

[26] G. Nemeth, J. Ekholm, and U. P. Arborelius, "Hip load moments and muscular activity during lifting," Scandinavian Journal of Rehabilitation Medicine, vol. 16, no. 3, pp. 103-111, 1984.

[27] G. Bergmann, F. Graichen, and A. Rohlmann, "Hip joint contact forces during stumbling," Langenbeck's Archives of Surgery, vol. 389, no. 1, pp. 53-59, 2004.

[28] G. Bergmann, F. Graichen, A. Rohlmann, and H. Linke, "Hip joint forces during load carrying," Clinical Orthopaedics and Related Research, no. 335, pp. 190-201, 1997.

[29] M. Kuster, S. Sakurai, and G. A. Wood, "Kinematic and kinetic comparison of downhill and level walking," Clinical Biomechanics, vol. 10, no. 2, pp. 79-84, 1995.

[30] S. J. G. Taylor and P. S. Walker, "Forces and moments telemetered from two distal femoral replacements during various activities," Journal of Biomechanics, vol. 34, no. 7, pp. 839-848, 2001.

[31] K. R. Kaufman, K. N. An, W. J. Litchy, B. F. Morrey, and E. Y. S. Chao, "Dynamic joint forces during knee isokinetic exercise," American Journal of Sports Medicine, vol. 19, no. 3, pp. 305-316, 1991.
[32] H. Rohrle, R. Scholten, and C. Sigolotto, "Joint forces in the human pelvis-leg skeleton during walking," Journal of Biomechanics, vol. 17, no. 6, pp. 409-424, 1984.

[33] R. Nisell, M. O. Ericson, G. Nemeth, and J. Ekholm, "Tibiofemoral joint forces during isokinetic knee extension," American Journal of Sports Medicine, vol. 17, no. 1, pp. 49-54, 1989.

[34] M. O. Ericson, A. Bratt, and R. Nisell, "Load moments about the hip and knee joints during ergometer cycling," Scandinavian Journal of Rehabilitation Medicine, vol. 18, no. 4, pp. 165-172, 1986.

[35] V. C. Mow and W. C. Hayes, Eds., Basic Orthopaedic Biomechanics, Raven Press, New York, NY, USA, 3rd edition, 2005.

[36] N. J. Dahlkvist, P. Mayo, and B. B. Seedhom, "Forces during squatting and rising from a deep squat," Engineering in Medicine, vol. 11, no. 2, pp. 69-76, 1982.

[37] S. J. G. Taylor, P. S. Walker, J. S. Perry, S. R. Cannon, and R. Woledge, "The forces in the distal femur and the knee during walking and other activities measured by telemetry," Journal of Arthroplasty, vol. 13, no. 4, pp. 428-437, 1998.

[38] R. F. Escamilla, "Knee biomechanics of the dynamic squat exercise," Medicine and Science in Sports and Exercise, vol. 33, no. 1, pp. 127-141, 2001.

[39] D. A. Winter, Biomechanics of Human Movement, Wiley, New York, NY, USA, 1990.

[40] M. S. Kuster, G. A. Wood, G. W. Stachowiak, and A. Gächter, "Joint load considerations in total knee replacement," Journal of Bone and Joint Surgery B, vol. 79, no. 1, pp. 109-113, 1997.

[41] C. R. Ratzlaff, M. Koehoorn, J. Cibere, and J. Kopec, "Clinical validation of an internet-based questionnaire for ascertaining cases of hip and knee osteoarthritis," Arthritis \& Rheumatism, vol. 62, supplement 10, p. S2093, 2010.

[42] R. Altman, G. Alarcon, D. Appelrouth et al., "The American College of Rheumatology criteria for the classification and reporting of osteoarthritis of the hip," Arthritis \& Rheumatism, vol. 34, no. 5, pp. 505-514, 1991.

[43] J. R. Landis and G. G. Koch, "The measurement of observer agreement for categorical data," Biometrics, vol. 33, no. 1, pp. 159-174, 1977.

[44] Y. Cheng, C. A. Macera, D. R. Davis, B. E. Ainsworth, P. J. Troped, and S. N. Blair, "Physical activity and self-reported, physician-diagnosed osteoarthritis: is physical activity a risk factor?" Journal of Clinical Epidemiology, vol. 53, no. 3, pp. 315-322, 2000.

[45] L. M. March, J. M. Schwarz, B. H. Carfrae, and E. Bagge, "Clinical validation of self-reported osteoarthritis," Osteoarthritis and Cartilage, vol. 6, no. 2, pp. 87-93, 1998.

[46] C. E. I. Szoeke, L. Dennerstein, A. E. Wluka et al., "Physician diagnosed arthritis, reported arthritis and radiological nonaxial osteoarthritis," Osteoarthritis and Cartilage, vol. 16, no. 7, pp. 846-850, 2008.

[47] D. T. Felson, R. C. Lawrence, P. A. Dieppe et al., "Osteoarthritis: new insights-part 1: the disease and its risk factors," Annals of Internal Medicine, vol. 133, no. 8, pp. 635-646, 2000.

[48] Y. Zhang and J. M. Jordan, "Epidemiology of osteoarthritis," Clinics in Geriatric Medicine, vol. 26, no. 3, pp. 355-369, 2010.

[49] D. T. Felson, J. J. Anderson, A. Naimark, A. M. Walker, and R. F. Meenan, "Obesity and knee osteoarthritis. The Framingham study," Annals of Internal Medicine, vol. 109, no. 1, pp. 18-24, 1988. 
[50] T. M. Griffin and F. Guilak, "Why is obesity associated with osteoarthritis? Insights from mouse models of obesity," Biorheology, vol. 45, no. 3-4, pp. 387-398, 2008.

[51] L. Sharma, D. Kapoor, and S. Issa, "Epidemiology of osteoarthritis: an update," Current Opinion in Rheumatology, vol. 18, no. 2, pp. 147-156, 2006.

[52] R. L. Imeokparia, J. P. Barrett, M. I. Arrieta et al., "Physical activity as a risk factor for osteoarthritis of the knee," Annals of Epidemiology, vol. 4, no. 3, pp. 221-230, 1994.

[53] E. C. Lau, C. Cooper, D. Lam, V. N. H. Chan, K. K. Tsang, and A. Sham, "Factors associated with osteoarthritis of the hip and knee in Hong Kong Chinese: obesity, joint injury, and occupational activities," American Journal of Epidemiology, vol. 152, no. 9, pp. 855-862, 2000.

[54] U. M. Kujala, J. Kettunen, H. Paananen et al., "Knee osteoarthritis in former runners, soccer players, weight lifters, and shooters," Arthritis \& Rheumatism, vol. 38, no. 4, pp. 539 546, 1995.

[55] A. J. Sutton, K. R. Muir, S. Mockett, and P. Fentem, "A case-control study to investigate the relation between low and moderate levels of physical activity and osteoarthritis of the knee using data collected as part of the Allied Dunbar National Fitness Survey," Annals of the Rheumatic Diseases, vol. 60, no. 8, pp. 756-764, 2001.

[56] L. Q. Rogers, C. A. Macera, J. M. Hootman, B. Ainsworth, and S. N. Blair, "The association between joint stress from physical activity and self-reported osteoarthritis: an analysis of the Cooper clinic data," Osteoarthritis and Cartilage, vol. 10, no. 8, pp. 617-622, 2002.

[57] J. M. Hootman, C. A. Macera, C. G. Helmick, and S. N. Blair, "Influence of physical activity-related joint stress on the risk of self-reported hip/knee osteoarthritis: a new method to quantify physical activity," Preventive Medicine, vol. 36, no. 5, pp. 636-644, 2003.

[58] E. Vingard, L. Alfredsson, I. Goldie, and C. Hogstedt, "Sports and osteoarthrosis of the hip. An epidemiologic study," American Journal of Sports Medicine, vol. 21, no. 2, pp. 195200, 1993.

[59] E. Vingard, C. Hogstedt, L. Alfredsson, E. Fellenius, I. Goldie, and M. Koster, "Coxarthrosis and physical work load," Scandinavian Journal of Work, Environment and Health, vol. 17, no. 2, pp. 104-109, 1991.

[60] C. Cooper, H. Inskip, P. Croft et al., "Individual risk factors for hip osteoarthritis: obesity, hip injury, and physical activity," American Journal of Epidemiology, vol. 147, no. 6, pp. 516-522, 1998.

[61] T. D. Spector, P. A. Harris, D. J. Hart et al., "Risk of osteoarthritis associated with long-term weight-bearing sports: a radiologic survey of the hips and knees in female exathletes and population controls," Arthritis \& Rheumatism, vol. 39, no. 6, pp. 988-995, 1996.

[62] A. T. Toivanen, M. Heliövaara, O. Impivaara et al., "Obesity, physically demanding work and traumatic knee injury are major risk factors for knee osteoarthritis-a population-based study with a follow-up of 22 years," Rheumatology, vol. 49, no. 2, pp. 308-314, 2009.

[63] L. M. Verweij, N. M. van Schoor, D. J. H. Deeg, J. Dekker, and M. Visser, "Physical activity and incident clinical knee osteoarthritis in older adults," Arthritis Care and Research, vol. 61, no. 2, pp. 152-157, 2009.

[64] Y. Wang, J. A. Simpson, A. E. Wluka et al., "Is physical activity a risk factor for primary knee or hip replacement due to osteoarthritis? A prospective cohort study," Journal of Rheumatology, vol. 38, no. 2, pp. 350-357, 2011.
[65] D. T. Felson, Y. Zhang, M. T. Hannan et al., "Risk factors for incident radiographic knee osteoarthritis in the elderly," Arthritis \& Rheumatism, vol. 40, no. 4, pp. 728-733, 1997.

[66] D. T. Felson, M. T. Hannan, A. Naimark et al., "Occupational physical demands, knee bending, and knee osteoarthritis: results from the Framingham study," Journal of Rheumatology, vol. 18, no. 10, pp. 1587-1592, 1991.

[67] T. E. McAlindon, P. W. F. Wilson, P. Aliabadi, B. Weissman, and D. T. Felson, "Level of physical activity and the risk of radiographic and symptomatic knee osteoarthritis in the elderly: the Framingham study," American Journal of Medicine, vol. 106, no. 2, pp. 151-157, 1999.

[68] M. T. Hannan, D. T. Felson, J. J. Anderson, and A. Naimark, "Habitual physical activity is not associated with knee osteoarthritis: the Framingham study," Journal of Rheumatology, vol. 20, no. 4, pp. 704-709, 1993.

[69] D. J. Hart, D. V. Doyle, and T. D. Spector, "Incidence and risk factors for radiographic knee osteoarthritis in middle-aged women: the Chingford study," Arthritis \& Rheumatism, vol. 42, no. 1, pp. 17-24, 1999.

[70] D. T. Felson, J. Nui, M. Clancy, B. Sack, P. Aliabadi, and Y. Zhang, "Effect of recreational physical activities on the development of knee osteoarthritis in older adults of different weights: the Framingham study," Arthritis Care and Research, vol. 57, no. 1, pp. 6-12, 2007.

[71] E. F. Chakravarty, H. B. Hubert, V. B. Lingala, E. Zatarain, and J. F. Fries, "Long distance running and knee osteoarthritis," American Journal of Preventive Medicine, vol. 35, no. 2, pp. 133-138, 2008.

[72] T. L. Racunica, A. J. Teichtahl, Y. Wang et al., "Effect of physical activity on articular knee joint structures in communitybased adults," Arthritis Care and Research, vol. 57, no. 7, pp. 1261-1268, 2007.

[73] E. W. Karlson, L. A. Mandl, G. N. Aweh, O. Sangha, M. H. Liang, and F. Grodstein, "Total hip replacement due to osteoarthritis: the importance of age, obesity, and other modifiable risk factors," American Journal of Medicine, vol. 114, no. 2, pp. 93-98, 2003.

[74] R. S. Panush, C. S. Hanson, J. R. Caldwell, S. Longley, J. Stork, and R. Thoburn, "Is running associated with osteoarthritis? An eight-year follow-up study," Journal of Clinical Rheumatology, vol. 1, no. 1, pp. 35-39, 1995.

[75] N. E. Lane, J. W. Oehlert, D. A. Bloch, and J. F. Fries, "The relationship of running to osteoarthritis of the knee and hip and bone mineral density of the lumbar spine: a 9 year longitudinal study," Journal of Rheumatology, vol. 25, no. 2, pp. 334-341, 1998.

[76] N. Thelin, S. Holmberg, and A. Thelin, "Knee injuries account for the sports-related increased risk of knee osteoarthritis," Scandinavian Journal of Medicine and Science in Sports, vol. 16, no. 5, pp. 329-333, 2006.

[77] J. A. Buckwalter and J. A. Martin, "Sports and osteoarthritis," Current Opinion in Rheumatology, vol. 16, no. 5, pp. 634-639, 2004.

[78] J. A. Buckwalter, "Sports, joint injury, and posttraumatic osteoarthritis," Journal of Orthopaedic and Sports Physical Therapy, vol. 33, no. 10, pp. 578-588, 2003.

[79] N. E. Lane and J. A. Buckwalter, "Exercise and osteoarthritis," Current Opinion in Rheumatology, vol. 11, no. 5, pp. 413-416, 1999.

[80] U. M. Kujala, J. Kaprio, and S. Sarna, "Osteoarthritis of weight bearing joints of low limbs in former elite male athletes," British Medical Journal, vol. 308, no. 6923, pp. 231234, 1994. 
[81] U. M. Kujala, P. Marti, J. Kaprio, M. Hernelahti, H. Tikkanen, and S. Sarna, "Occurrence of chronic disease in former toplevel athletes: predominance of benefits, risks or selection effects?" Sports Medicine, vol. 33, no. 8, pp. 553-561, 2003.

[82] J. M. Jordan, C. G. Helmick, J. B. Renner et al., "Prevalence of knee symptoms and radiographic and symptomatic knee osteoarthritis in African Americans and Caucasians: the Johnston County Osteoarthritis project," Journal of Rheumatology, vol. 34, no. 1, pp. 172-180, 2007.

[83] C. F. Dillon, E. K. Rasch, Q. Gu, and R. Hirsch, "Prevalence of knee osteoarthritis in the United States: arthritis data from the Third National Health and Nutrition Examination Survey 1991-94," Journal of Rheumatology, vol. 33, no. 11, pp. 2271-2279, 2006.

[84] D. T. Felson, A. Naimark, and J. Anderson, "The prevalence of knee osteoarthritis in the elderly. the Framingham Osteoarthritis study," Arthritis \& Rheumatism, vol. 30, no. 8, pp. 914-918, 1987.

[85] B. E. Ainsworth, "Issues in the assessment of physical activity in women," Research Quarterly for Exercise and Sport, vol. 71, supplement 2, pp. S37-S42, 2000.

[86] A. E. Cust, B. K. Armstrong, C. M. Friedenreich, N. Slimani, and A. Bauman, "Physical activity and endometrial cancer risk: a review of the current evidence, biologic mechanisms and the quality of physical activity assessment methods," Cancer Causes and Control, vol. 18, no. 3, pp. 243-258, 2007.

[87] B. E. Ainsworth, "Challenges in measuring physical activity in women," Exercise and Sport Sciences Reviews, vol. 28, no. 2, pp. 93-96, 2000.

[88] R. R. Pate, M. Pratt, S. N. Blair et al., "Physical activity and public health: a recommendation from the Centers for Disease Control and Prevention and the American College of Sports Medicine," Journal of the American Medical Association, vol. 273, no. 5, pp. 402-407, 1995.

[89] H. Sandmark, C. Hogstedt, and E. Vingård, "Primary osteoarthrosis of the knee in men and women as a result of lifelong physical load from work," Scandinavian Journal of Work, Environment and Health, vol. 26, no. 1, pp. 20-25, 2000.

[90] I. Weller and P. Corey, "The impact of excluding non-leisure energy expenditure on the relation between physical activity and mortality in women," Epidemiology, vol. 9, no. 6, pp. 632-635, 1998.

[91] C. M. Friedenreich, H. E. Bryant, and K. S. Courneya, "Casecontrol study of lifetime physical activity and breast cancer risk," American Journal of Epidemiology, vol. 154, no. 4, pp. 336-347, 2001.

[92] A. M. Lievense, S. M. A. Bierma-Zeinstra, A. P. Verhagen, R. M. D. Bernsen, J. A. N. Verhaar, and B. W. Koes, "Influence of sporting activities on the development of osteoarthritis of the hip: a systematic review," Arthritis Care and Research, vol. 49, no. 2, pp. 228-236, 2003.

[93] A. Lievense, S. Bierma-Zeinstra, A. Verhagen, J. Verhaar, and B. Koes, "Influence of work on the development of osteoarthritis of the hip: a systematic review," Journal of Rheumatology, vol. 28, no. 11, pp. 2520-2528, 2001.

[94] E. Vignon, J. P. Valat, M. Rossignol et al., "Osteoarthritis of the knee and hip and activity: a systematic international review and synthesis (OASIS)," Joint Bone Spine, vol. 73, no. 4, pp. 442-455, 2006.

[95] A. B. HILL, "The environment and disease: association or causation?" Proceedings of the Royal Society of Medicine, vol. 58, pp. 295-300, 1965.
[96] A. M. Kriska, W. C. Knowler, R. E. LaPorte et al., "Development of questionnaire to examine relationship of physical activity and diabetes in Pima Indians," Diabetes Care, vol. 13, no. 4, pp. 401-411, 1990.

[97] C. W. Wu, M. R. Morrell, E. Heinze et al., "Validation of American College of Rheumatology classification criteria for knee osteoarthritis using arthroscopically defined cartilage damage scores," Seminars in Arthritis \& Rheumatism, vol. 35, no. 3, pp. 197-201, 2005.

[98] J. Bedson and P. R. Croft, "The discordance between clinical and radiographic knee osteoarthritis: a systematic search and summary of the literature," BMC Musculoskeletal Disorders, vol. 9, article 116, 2008.

[99] P. Ritter, K. Lorig, D. Laurent, and K. Matthews, "Internet versus mailed questionnaires: a randomized comparison," Journal of Medical Internet Research, vol. 6, no. 3, p. e29, 2004.

[100] M. A. Stopponi, G. L. Alexander, J. B. McClure et al., "Recruitment to a randomized web-based nutritional intervention trial: characteristics of participants compared to nonparticipants," Journal of Medical Internet Research, vol. 11, no. 3, p. e38, 2009.

[101] G. Eysenbach, "Improving the quality of Web surveys: the Checklist for Reporting Results of Internet E-Surveys (CHERRIES)," Journal of Medical Internet Research, vol. 6, no. 3, p. e34, 2004.

[102] K. F. Janz, "Physical activity in epidemiology: moving from questionnaire to objective measurement," British Journal of Sports Medicine, vol. 40, no. 3, pp. 191-192, 2006.

[103] A. M. Kriska, R. B. Sandler, J. A. Cauley, R. E. LaPorte, D. L. Hom, and G. Pambianco, "The assessment of historical physical activity and its relation to adult bone parameters," American Journal of Epidemiology, vol. 127, no. 5, pp. 10531063, 1988.

[104] R. J. Shephard, "Limits to the measurement of habitual physical activity by questionnaires," British Journal of Sports Medicine, vol. 37, no. 3, pp. 197-206, 2003.

[105] C. M. Friedenreich, "Improving long-term recall in epidemiologic studies," Epidemiology, vol. 5, no. 1, pp. 1-4, 1994.

[106] L. Chasan-Taber, J. Bianca Erickson, P. C. Nasca, S. ChasanTaber, and P. S. Freedson, "Validity and reproducibility of a physical activity questionnaire in women," Medicine and Science in Sports and Exercise, vol. 34, no. 6, pp. 987-992, 2002.

[107] G. Godin, J. Jobin, and J. Bouillon, "Assessment of leisure time exercise behavior by self-report: a concurrent validity study," Canadian Journal of Public Health, vol. 77, no. 5, pp. 359-362, 1986.

[108] F. Guilak, L. A. Setton, and V. B. Kraus, "Structure and function of articular cartilage," in Principles and Practice of Orthopaedic Sports MEdicine, W. E. J. Garrett, K. P. Speer, and D. T. Kirkendall, Eds., pp. 53-73, Lippincott Williams \& Wilkins, Philadelphia, Pa, USA, 2000.

[109] K. D. Brandt, P. Dieppe, and E. L. Radin, "Etiopathogenesis of osteoarthritis," Rheumatic Disease Clinics of North America, vol. 34, no. 3, pp. 531-559, 2008.

[110] T. M. Griffin and F. Guilak, "The role of mechanical loading in the onset and progression of osteoarthritis," Exercise and Sport Sciences Reviews, vol. 33, no. 4, pp. 195-200, 2005.

[111] G. Pap, R. Eberhardt, I. Stürmer et al., "Development of osteoarthritis in the knee joints of Wistar rats after strenuous running exercise in a running wheel by intracranial selfstimulation," Pathology Research and Practice, vol. 194, no. 1, pp. 41-47, 1998. 
[112] C. T. Chen, N. Burton-Wurster, G. Lust, R. A. Bank, and J. M. Tekoppele, "Compositional and metabolic changes in damaged cartilage are peak- stress, stress-rate, and loadingduration dependent," Journal of Orthopaedic Research, vol. 17, no. 6, pp. 870-879, 1999. 


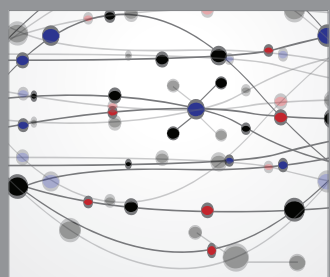

The Scientific World Journal
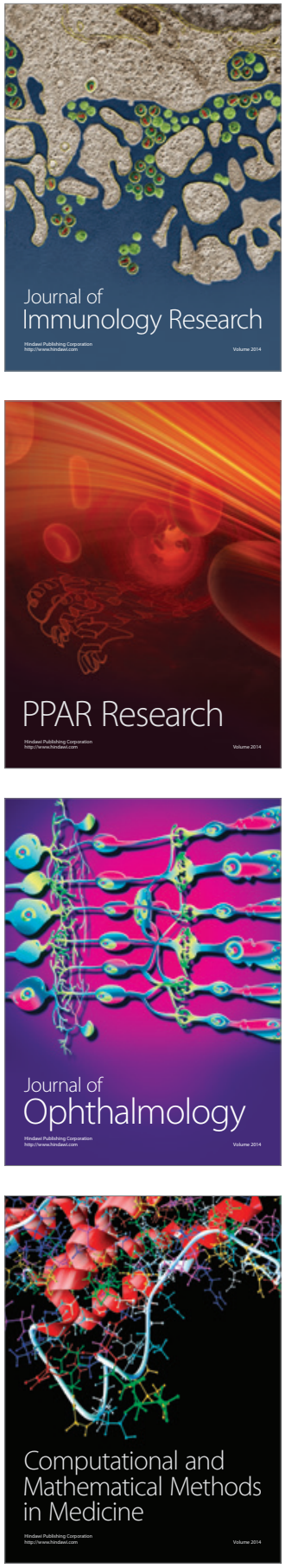

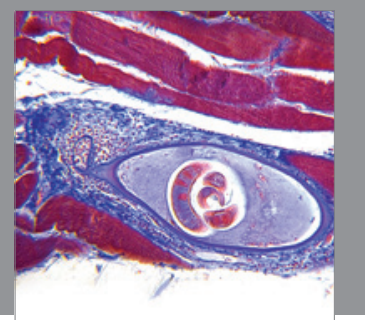

Gastroenterology

Research and Practice
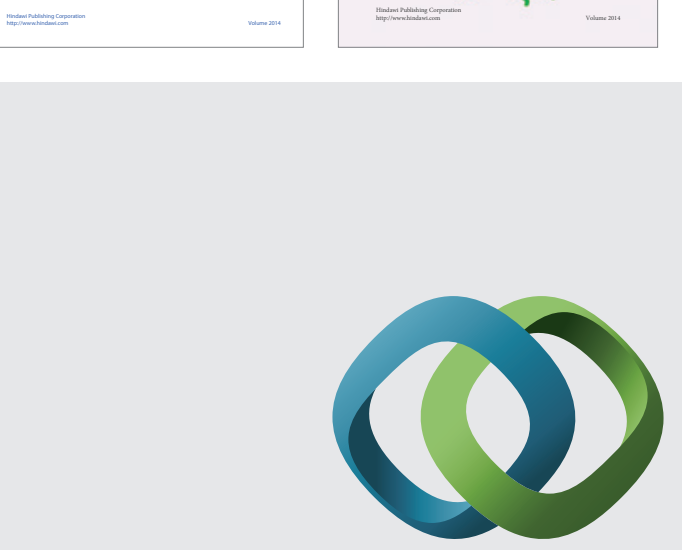

\section{Hindawi}

Submit your manuscripts at

http://www.hindawi.com
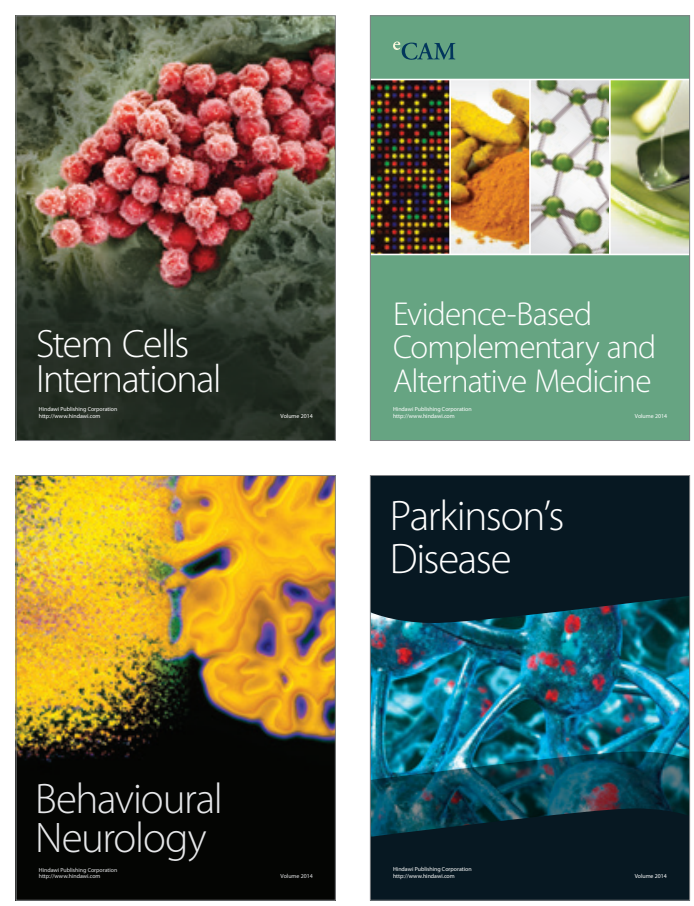

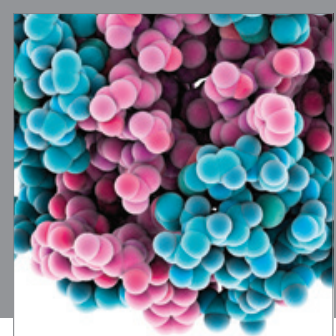

Journal of
Diabetes Research

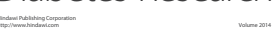

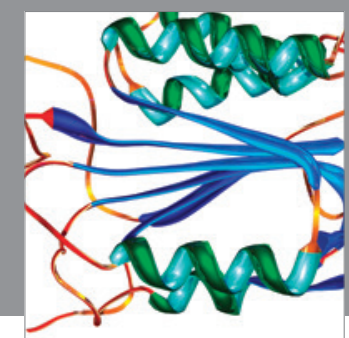

Disease Markers
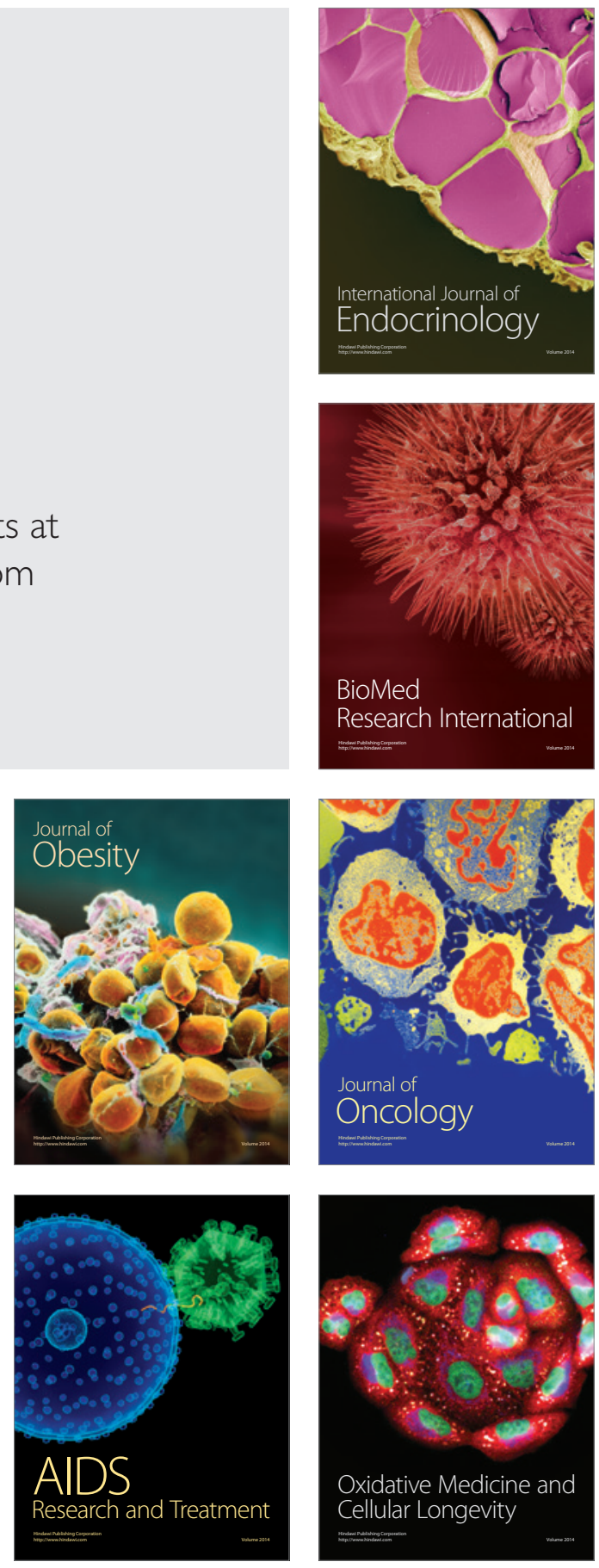